\title{
Relationships among lipid peroxidation, $S O D$ enzyme activity, and $S O D$ gene expression profile in Lycopersicum esculentum L. exposed to cold stress
}

\author{
S. Soydam Aydin' ${ }^{1}$ İ. Büyük ${ }^{2}$ and S. Aras ${ }^{2}$ \\ ${ }^{1}$ Laboratory of Biological Control, \\ Department of Medicine, Biology and Medical Production, \\ Ministry of Health of Turkey, \\ General Directorate of Pharmaceuticals and Pharmacy, Ankara, Turkey \\ ${ }^{2}$ Department of Biology, Faculty of Science, Ankara University, \\ Ankara, Turkey
}

Corresponding author: S. Soydam Aydin

E-mail: semrasoydam@gmail.com

Genet. Mol. Res. 12 (3): 3220-3229 (2013)

Received January 29, 2013

Accepted July 16, 2013

Published August 29, 2013

DOI http://dx.doi.org/10.4238/2013.August.29.6

\begin{abstract}
The current study was designed to evaluate lipid peroxidation (via malondialdehyde) levels, the superoxide dismutase $(S O D)$ gene expression profile, and $S O D$ enzyme activity in tomato plants (Lycopersicum esculentum L.) subjected to different time periods of cold stress (control, 2, 4, 6, 8, and 10 days). Results revealed that maximum lipid peroxidation occurred in plants exposed to cold stress for 10 days, and $S O D$ enzyme activity gradually increased with increasing exposure to cold stress. The level of mRNA increased within 4 days of cold treatment. After this period, the level tended to decrease and reached a minimum by the eighth day. A complex gene expression profile was determined, which was not statistically significant until the eighth day. At the 10th day of cold treatment, the mRNA level of $S O D$ increased and changes between the 8th and 10th day were found to be statistically significant at the $\mathrm{P}<0.05$ level. These results suggest that
\end{abstract}


the $S O D$ gene and enzyme play a key role in resistance to cold stress conditions in tomato plants.

Key words: Cold stress; Superoxide dismutase; Enzyme activity; Real-time PCR; Tomato; Lycopersicum esculentum L.

\section{INTRODUCTION}

The rapidly growing world population has made it necessary to prevent losses in crop productivity (Tester and Davenport, 2003; Mazzucotelli et al., 2008). Plants are exposed to a wide array of environmental stress factors, such as drought, heat, cold, ultraviolent light, air pollution, and pathogen attacks among others (McKersie and Leshem, 1994; Pinheiro et al., 1997). Among these various abiotic stresses, cold is one of the most significant limitations to growth, affecting many genetic, physiological, and biochemical responses in plants. These responses include: changes in membrane composition, photosynthetic efficiency, accumulation of sugar or other compounds, closure of stoma, production of small molecules and free radicals, and alterations in the activities of antioxidant enzymes and their gene expressions (Beck et al., 2007; Tian et al., 2011).

In response to stomatal closure and limited $\mathrm{CO}_{2}$ availability, chloroplasts, mitochondria, and peroxisomes generate reactive oxygen species (ROS), such as $\mathrm{O}_{2}^{-}, \mathrm{H}_{2} \mathrm{O}_{2},{ }^{1} \mathrm{O}_{2}, \mathrm{HO}_{2}^{-}, \mathrm{OH}$, $\mathrm{ROOH}, \mathrm{ROO}$, and RO, which can all act as oxidative damaging factors at the cellular level. On the other hand, a protective or signaling factor depends on the equilibrium between ROS production and scavenging or defense mechanisms (Smirnoff, 1993; Mittler, 2002).

For scavenging of ROS, plants have antioxidant mechanisms that are divided into two components: non-enzymatic antioxidants and enzymatic antioxidant systems. The non-enzymatic antioxidants include glutathione, proline, carotenoids, and tocopherol, and the enzymatic antioxidants include monodehydroascorbate reductase, dehydroascorbate reductase, glutathione reductase (GR), ascorbate peroxidase (APX), catalase, and superoxide dismutase (SOD) (Verma and Dubey, 2003; DalCorso et al., 2008).

$S O D$ plays a determinant role in protection against the toxic effects of oxidative stress by scavenging superoxide radicals and promoting their conversion into oxygen and hydrogen peroxide. Four different classes of $S O D s$ have been distinguished, depending on the metal present at the active center: manganese $(\mathrm{Mn})$, iron $(\mathrm{Fe})$, copper $(\mathrm{Cu})$, or zinc $(\mathrm{Zn}) . \mathrm{Cu} / \mathrm{Zn}$ SODs are generally found in the cytosol of eukaryotic cells and chloroplasts, Mn SODs are found in mitochondria, chloroplasts, and peroxisomes, and the dimeric Fe SODs, which are not present in animal cells, are found in chloroplasts (Droillard and Paulin, 1990; Van Camp et al., 1994; Fridovich, 1995).

In the current study, the gene expression profile of the SOD enzyme was analyzed at the mRNA level by real-time reverse transcription-polymerase chain reaction (RT-PCR) in tomato (Lycopersicum esculentum L. 'Falcon') samples exposed to cold stress for various time intervals. To gain information about the regulation of the $S O D$ gene product, enzyme activities in the samples were also evaluated.

Modern methods such as real-time RT-PCR and microarray hybridization allow precise measurements of mRNA steady-state levels. Real-time RT-PCR provides advantages, such as very high sensitivity and precise quantification of mRNA levels of genes of interest when expression levels are compared under different conditions or treatments. The control of gene expression in all cells involves various molecules, including RNA polymerases, numerous tran- 
scription factors, the DNA template, the RNA produced by transcription, and the protein produced by translation with its attendant processing. The examination of gene expression often involves quantifying the abundance of a particular transcript. Real-time RT-PCR, like other methods such as Northern hybridization, does not provide information about the transcriptional activity of genes, but measures only steady-state levels, i.e., the final accumulation of RNA in the cell at the moment of lysis. These methods fail to take into account the stability of the RNA, as well as the rate of transcription at the specific loci under investigation. In order to describe the nature of gene expression modulation in more depth, it is necessary to examine the level of the corresponding protein so as to determine whether alterations in transcript levels, protein levels, or both are in some way associated with phenotypic change (Farrell, 2007). In this regard, in the current study, experiments were conducted in three phases after cold stress treatments. In the first part, in order to obtain evidence that plants were in stress, malondialdehyde (MDA) levels were determined following the cold treatments. Small hydrocarbon fragments, such as ketones, MDAs, and related compounds, have been used as indicators of lipid peroxidation or membrane damage, which are considered as the first evidence of stress in plants (Lyons, 1973). In the second part of the study, the abundance of the steady-state level of SOD mRNA was determined by quantitative real-time PCR. Finally, in the third part, $S O D$ enzyme activities were determined in order to obtain insight into the final stage of $S O D$ gene expression in tomato samples exposed to different time periods of cold stress.

Consequently, this study will help to clarify the response mechanisms of SOD to cold stress in L. esculentum, and will provide a foundation for future studies related to the role and mechanism of $S O D$ enzymes during cold stress tolerance.

\section{MATERIAL AND METHODS}

\section{Plant material, growth conditions, and stress treatment}

Tomato (L. esculentum) seeds were germinated and grown hydroponically in pots containing $0.2 \mathrm{~L}$ modified 1/10 Hoagland's solution. Hoagland's solution includes macronutrients $\left[\mathrm{K}_{2} \mathrm{SO}_{4}, \mathrm{KH}_{2} \mathrm{PO}_{4}, \mathrm{MgSO}_{4} \cdot 7 \mathrm{H}_{2} \mathrm{O}, \mathrm{Ca}\left(\mathrm{NO}_{3}\right)_{2} \cdot 4 \mathrm{H}_{2} \mathrm{O}\right.$, and $\left.\mathrm{KCl}\right]$ and micronutrients $\left(\mathrm{H}_{3} \mathrm{BO}_{3}\right.$, $\mathrm{MnSO}_{4}, \mathrm{CuSO}_{4} \cdot 5 \mathrm{H}_{2} \mathrm{O}, \mathrm{NH}_{4} \mathrm{Mo}$, and $\mathrm{ZnSO}_{4} \cdot 7 \mathrm{H}_{2} \mathrm{O}$ ) with the following final concentrations of ions: $2 \mathrm{mM} \mathrm{Ca}, 1 \mu \mathrm{M} \mathrm{Mn}, 4 \mathrm{mM} \mathrm{NO}, 0.2 \mu \mathrm{M} \mathrm{Cu}, 1 \mathrm{mM} \mathrm{Mg}, 10 \mathrm{nM} \mathrm{NH}_{4}, 2 \mathrm{mM} \mathrm{K}, 1 \mu \mathrm{M}$ $\mathrm{Zn}, 0.2 \mathrm{mM} \mathrm{P}, 0.1 \mathrm{mM} \mathrm{Fe}$, and $1 \mu \mathrm{M} \mathrm{B}$. Six plants were grown in each pot in a controlled environmental growth chamber under $250 \mathrm{mmol} \cdot \mathrm{m}^{-2} \cdot \mathrm{s}^{-1}$ photosynthetic photon flux at $25^{\circ} \mathrm{C}$ and $70 \%$ relative humidity. Twenty-five-day-old plants grown in controlled media were used for stress treatments. For application of cold stress, plants were exposed to $4^{\circ} \mathrm{C}$ and samples were collected at different time periods (control, 2, 4, 6, 8, and 10 days). Cold stress-treated whole tomato plants (total leaves, stems, and roots) were ground in liquid nitrogen and used for estimation of lipid peroxidation, protein extraction, $S O D$ enzyme activity assays, RNA extraction, and gene expression analysis.

\section{Estimation of lipid peroxidation}

MDA is a marker of oxidative lipid injury as it changes in response to environmental factors that lead to stress in plants. Thiobarbituric acid (TBA)-MDA content was determined as 
described by Hodges et al. (1999). Plant tissue samples were homogenized in liquid nitrogen and homogenized with 80:20 (v:v) ethanol:water, followed by centrifugation at $3000 \mathrm{~g}$ for $10 \mathrm{~min}$. A 1-mL aliquot appropriately diluted sample was added to a test tube containing $1 \mathrm{~mL}$ either TBA solution containing $20.0 \%(\mathrm{w} / \mathrm{v})$ trichloroacetic acid and $0.01 \%$ butylated hydroxytoluene or + TBA solution, containing the same components as above with the addition of $0.65 \%$ TBA. Samples were then mixed vigorously, heated at $95^{\circ} \mathrm{C}$ in a hot plate (neoBlock1, 2-2503) for 25 $\mathrm{min}$, cooled, and centrifuged at $3000 \mathrm{~g}$ for $10 \mathrm{~min}$. Absorbance values were measured at 440, 532, and $600 \mathrm{~nm}$ on an enzyme linked immunosorbent assay (ELISA) microplate reader (SpectraMax M2). The equivalents of MDA were calculated using the following equations:

$$
\begin{aligned}
& \left.\left[\left(\text { Abs } 532_{+\mathrm{TBA}}\right)-\left(\text { Abs } 600_{+\mathrm{TBA}}\right)-\left(\text { Abs } 532_{-\mathrm{TBA}}-\mathrm{Abs} 600_{-\mathrm{TBA}}\right)\right]=\mathrm{A} \quad \text { (Equation } 1\right) \\
& {\left[\left(\operatorname{Abs} 440_{+\mathrm{TBA}}-\mathrm{Abs} 600_{+\mathrm{TBA}}\right) 0.0571\right]=\mathrm{B} \quad \text { (Equation 2) }} \\
& \text { MDA equivalents }(\mathrm{nM})=(\mathrm{A}-\mathrm{B} / 157,000) \times 10^{6} \quad \text { (Equation 3) }
\end{aligned}
$$

\section{RNA extraction and gene expression analysis with real-time quantitative PCR}

RNA extraction was performed with the Trizol protocol according to the RNeasy Mini Kit (Qiagen, Cat No. 74104) cleanup (Chomczynski and Mackey, 1995). The quantity and quality of RNA were determined on a Nanodrop ND-Spectrometer 1000 and confirmed by gel electrophoresis, which contained $1.5 \%$ agarose and formaldehyde. A two-step procedure was used for real-time RT-PCR. Reverse transcription reactions were performed with $2 \mu \mathrm{g}$ RNA, $2.5 \mu \mathrm{M}$ anchored-oligo(dT)18, 1X Transcriptor High-Fidelity Reverse Transcriptase Reaction Buffer, 20 U Protector Rnase Inhibitor, $1 \mathrm{mM}$ deoxynucleotide mix, $5 \mathrm{mM}$ DTT, and $10 \mathrm{U}$ Transcriptor High-Fidelity Reverse Transcriptase, using the High-Fidelity cDNA Synthesis Kit (Roche).

Real-time PCR was performed on a Light Cycler 480 System (Roche). The sequences of primers and probes (Table 1) of the target gene $(S O D)$ and the actin $(A C T)$ gene, used for normalization, were designed based on sequences of tomato genes available in the National Center for Biotechnology Information (NCBI) database (http://www.ncbi.nlm.nih.gov/). These sequences are common sequences of four different classes of $S O D s$, which are located in the cytosol, chloroplasts, mitochondria, and peroxisomes of tomato cells. Amplifications of PCR products were monitored via intercalation of hybridization probes. Copy numbers of genes ( $S O D$ and $A C T)$ under stress treatments were determined using standard curves.

\begin{tabular}{ll}
\multicolumn{1}{c}{ Table 1. Primer and probe sequences of superoxide dismutase $(S O D)$ and actin $(\mathrm{ACT})}$. \\
\hline SOD F Fw & gAgCTTgAggATgACCTCg \\
SOD S Fw & CTTgAggATgACCTCggAAA \\
SOD A Rev & TgTTgCTgCTgCATTTACTTC \\
SOD R Rev & CCggAgAgAggTAAATAC \\
SOD FL & TgCCAATCgTCCACCAgCAT \\
SOD LC 640 & gCCAgTggTAAgACTgAgTTCATggCC \\
ACT F Fw & CATTgTCCACAgAAAgTgCTTCTA \\
$A C T$ S Fw & TCTgTTTCCCggTTTgCTATTAT \\
ACT A Rev & AACCACATTAAATggAAACATgAgAT \\
$A C T$ R Rev & TgCATCAggCACCTCTCAAg \\
$A C T$ FL & ATTCATAgCCCCCACCACCAAAC \\
$A C T$ LC 640 & TCTCCATCCCATCAAAAAAACAAATgACT \\
\hline
\end{tabular}




\section{Protein extraction and SOD enzyme activity assays}

Whole samples exposed to different time periods of cold stress were homogenized with 1:1 (w/v) $0.2 \mathrm{M}$ phosphate buffer, $\mathrm{pH} 7.0$, with a cold mortar and pestle. The homogenate was centrifuged at $27,000 \mathrm{~g}$ for $20 \mathrm{~min}$. The supernatant was used for assays of total soluble protein content according to the Bradford method, using bovine serum albumin as a standard (Bradford, 1976). All extracts were assayed for SOD activity photochemically at $440 \mathrm{~nm}$, using the $S O D$ determination kit, which enables $S O D$ assaying with Dojindo's highly water soluble tetrazolium salt, WST-1 (2-3-5 -2H tetrazolium salt, monosodium salt), that produces a water soluble formazan dye upon reduction with a superoxide anion. The absorbance at $440 \mathrm{~nm}$ is proportional to the amount of superoxide anions present, and the $S O D$ activity can be quantified by measuring the decrease in color development at 440 nm (Sigma Aldrich 19160).

\section{Statistical analysis}

The abundance of target gene transcripts was normalized to that of $A C T$ and set relative to control plants according to the $2^{-\Delta \Delta C T}$ method (Livak and Schmittgen, 2001). Changes in relative expression levels of the gene were checked for statistical significance with one-way analysis of variance (ANOVA). The results were considered to be statistically significant if $P$ $<0.05$ in the Dunnett test.

\section{RESULTS}

\section{Estimation of lipid peroxidation}

MDA analysis was used as an indicator of lipid peroxidation or membrane damage, which is considered as the first evidence of cold stress in plants. MDA contents of tomato samples treated with different time periods of cold stress are shown in Figure 1. All time periods of cold stress caused an increase in MDA contents in tomato plants. The minimum MDA level was observed in tomato plants exposed to cold stress for 2 days, and the maximum MDA content $(45.20 \%)$ was observed in plants exposed to cold stress for 10 days. The MDA content of L. esculentum samples in all time periods (control, 2, 4, 6, 8, and 10 days) were determined to be $7.38,8.56,24.89,39.69,41.70$, and $45.20 \%$, respectively (Table 2).

Table 2. Effect of cold stress on malondialdehyde (MDA) content (\%), inhibition of water soluble tetrazolium salt (WST-1) (\%), and gene expression level of superoxide dismutase (SOD) (fold-change) in tomato after different time periods of cold stress.

\begin{tabular}{lccc}
\hline Time period & MDA content $(\%)$ & Inhibition of WST-1 (\%) & Gene expression of SOD (fold-change) \\
\hline Control & 7.38 & 17.47 & 1.00 \\
2 days & 8.56 & 8.89 & 0.86 \\
4 days & 24.89 & 10.22 & 1.17 \\
6 days & 39.69 & 21.80 & 0.67 \\
8 days & 41.70 & 33.59 & 0.38 \\
10 days & 45.20 & 37.77 & 1.05 \\
\hline
\end{tabular}




\section{Real-time quantitative RT-PCR}

The mRNA expression levels of the $S O D$ and $A C T$ genes were analyzed in L. esculentum samples with real-time PCR (Light Cycler ${ }^{\mathrm{B}} 480$ System, Roche), and the results are summarized in Figure 2. SOD gene transcript levels were calculated in tomato samples exposed to various time intervals of cold stress.

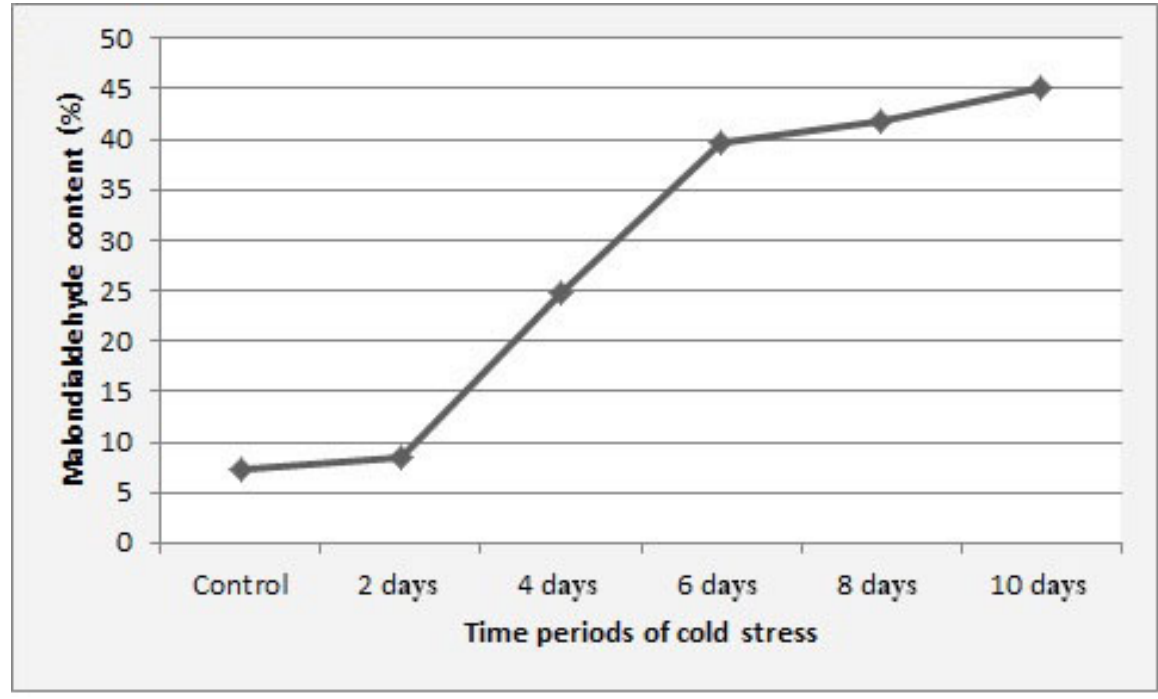

Figure 1. Lipid peroxidation (malondialdehyde content) in tissues of Lycopersicum esculentum samples exposed to different time periods of cold stress.

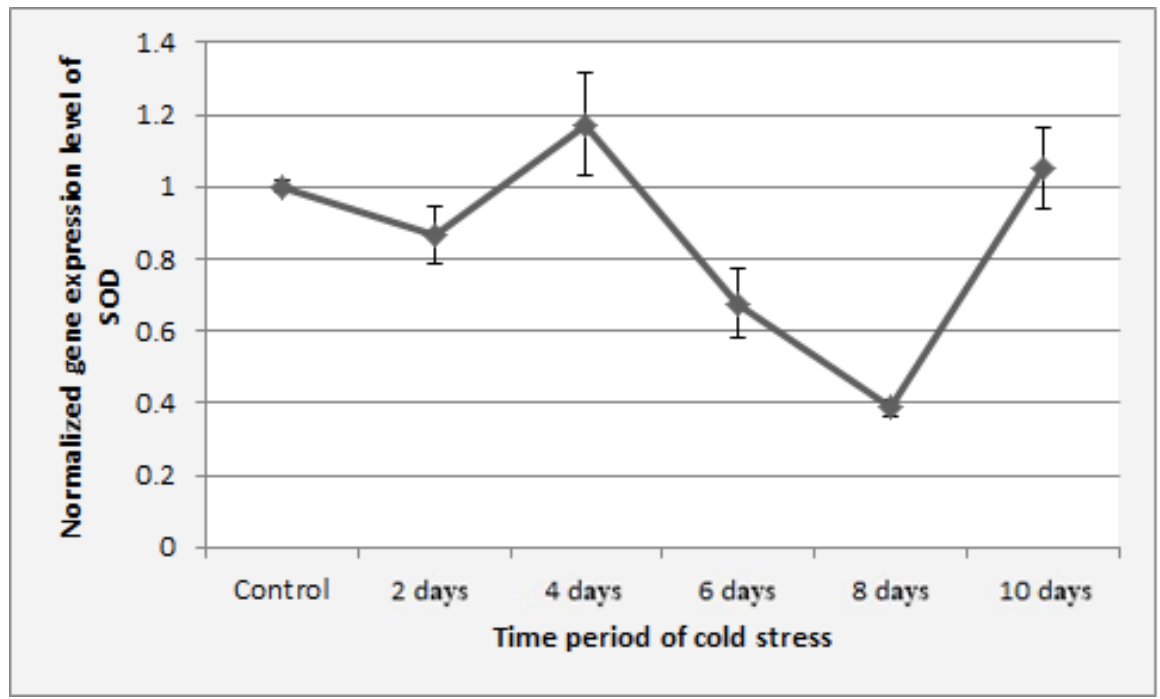

Figure 2. Superoxide dismutase (SOD) gene expression profile in Lycopersicum esculentum samples exposed to different time periods of cold stress. 
To avoid error, real-time RT-PCR is typically normalized with $A C T$ as a housekeeping and internal control gene along with control samples. To evaluate the stability of the results, $S O D$ and $A C T$ transcript levels of all samples were measured three times for each time period. With regard to the control and to each other, different expression levels were recorded in all time periods of the cold treatments. Results revealed that the level of SOD gene transcripts decreased in the first time period ( 2 days) of cold treatment. Subsequently, the level increased 1.17-fold compared to that of the control in 4 days cold-treated tomato samples. Following the recovery period, a decrease in $S O D$ expression was observed in the samples exposed to cold stress for 6 and 8 days, and these decreases were compatible with plasmolysis observed in leaves of tomato samples. The changes in the expression levels of $S O D$ were not significant, except at 8 days of cold treatment, which was significantly reduced by 0.38 -fold compared to the control $(\mathrm{P}<0.001)$.

\section{SOD enzyme activity assays}

To verify the responses of the tomato plants to different time periods of cold stress, differences in the enzyme activity of $S O D$ were determined based on inhibition of WST-1, and the results are shown in Figure 3. Tomato plants that were cold stressed for 2 and 4 days displayed significant inhibition in the WST-1 rate, indicating that $S O D$ enzyme activity was strongly reduced. Furthermore, although $S O D$ enzyme activity was significantly decreased in the short time period of stress ( 2 and 4 days), long periods of cold stress $(6,8$, and 10 days) resulted in an increase in enzyme activity compared to control plants. SOD enzyme activities gradually increased with increasing time of cold stress, and an almost directly proportional relationship was found between enzyme activity and MDA content of L. esculentum samples.

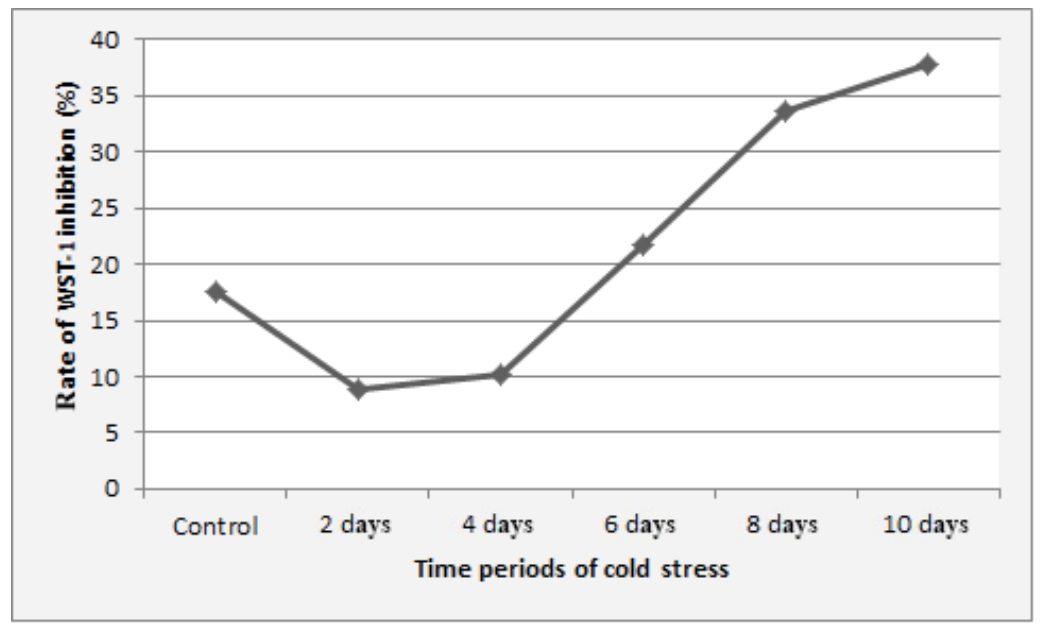

Figure 3. Levels of superoxide dismutase (SOD) enzyme activity in Lycopersicum esculentum samples exposed to different time periods of cold stress. WTS1 $=$ water soluble tetrazolium salt.

\section{DISCUSSION}

In the current study, we analyzed the effects of cold stress on the cell membrane, $S O D$ 
enzyme activity, and gene expression profile in tomato plants ( $L$. esculentum). Cold stress is known to be related to ROS accumulation. Increased ROS levels in plants exposed to stress might indicate unsaturation in membrane lipids, modification in membrane composition, fluidity, and permeability, or differentiation in cell wall-modifying enzyme activities, which can all lead to lipid peroxidation (Horvath et al., 1998; Örvar et al., 2000; Brummell et al., 2004). Increased lipid peroxidation has been reported in many plants under different environmental stresses (Moran et al., 1994; Prasad, 1996; Gülen et al., 2008), including cold stress (Posmyk et al., 2005; Xu et al., 2010). MDA contents, as an indicator of lipid peroxidation, are generally considered as the first evidence of cold stress in plants (Lyons, 1973). Results of the current study indicated that MDA content substantially increased with elongated time periods of cold stress. The maximum level of MDA (45.20\%) was attained in the samples exposed to cold stress for 10 days (Table 2 and Figure 1). The results also showed that ROS-induced lipid peroxidation started quickly after cold stress was induced, and the level of the injury depended on the total exposure time.

ROS have dual actions, acting both as oxidative damaging factors at the cellular level and as protective or signaling factors, depending on the equilibrium between ROS production and scavenging or defense mechanisms (Mittler, 2002). Plants have several antioxidant enzymes and metabolites located in various cellular compartments, the most significant being $S O D s$, a family of metalloenzymes that catalyze the dismutation of $\mathrm{O}_{2}^{-}$to $\mathrm{H}_{2} \mathrm{O}_{2}$ (Dat et al., 2000). SOD plays a significant role in scavenging superoxide radicals and promoting their conversion into oxygen and hydrogen peroxide, and its activity has been associated with temperature stress (Rao et al., 1996). The effects of antioxidant enzymes under different abiotic stresses have been demonstrated in several previous studies (Lee et al., 2000; Zhang et al., 2004; Wu et al., 2004). The current study revealed that the antioxidant responses of plants to cold stress could be reflected as changes in gene transcripts and enzyme activities of SOD.

Overexpression of antioxidant genes, such as GR, $A P X, S O D$, etc., have been demonstrated to provide enhanced tolerance to ROS-induced stress in several crop species (Roxas et al., 2000; Shinozaki and Yamaguchi-Shinozaki, 2000; Payton et al., 2001; Dai et al., 2009; Goupil et al., 2009; Fortunato et al., 2010). Different gene encoding factors involved in signal transduction cascades, such as transcription factors, are induced by stress treatments, which in turn might affect expression patterns of antioxidant genes (Shinozaki and Yamaguchi-Shinozaki, 1996). Several methods are currently being used to analyze gene expression profiles in plants. In the current study, the differential expression pattern of the $S O D$ gene with respect to cold stress was analyzed with real-time PCR. The sequences of primers and probes (Table 1) of the target gene are common sequences of four different classes of SODs located in the cytosol, chloroplasts, mitochondria, and peroxisomes of tomato cells, which in turn provides global information about the expression levels of $S O D$ isoenzymes in the whole plant. Analysis of gene expression patterns during cold stress treatments showed a complex profile. The level of mRNA increased within 4 days of cold treatment. After this time period, the level tended to decrease, and reached a minimum at 8 days. When we analyzed this complex profile of gene expression, the changes were found to be statistically insignificant until 8 days of cold stress treatment. At 10 days, the mRNA level of SOD increased and the changes between 8 and 10 days were found to be statistically significant at the $\mathrm{P}<0.05$ level.

$S O D$ gene expression patterns at the mRNA level were not positively correlated to changes in SOD enzyme activities under different conditions of cold treatment. For example, although the steady-state level of mRNA decreased slightly after 4 days of cold treatment and reached a 
statistically important level at 8 days (compared to the control), a gradual increase was observed in enzyme activity levels until the 10th day (Figures 2 and 3 ). These results suggest regulation of $S O D$ gene expression at the translational or post-translational levels until 8 days of cold exposure. Increased stability of proteins at low temperatures (Privalov, 1990) might explain the observed increase in enzyme activity. However, at 10 days, a sharp increase was also observed in the mRNA level (Figure 2), suggesting a need for new transcripts or increased stability of nascently transcribed mRNAs. In other words, transcriptional or post-transcriptional levels of control of SOD gene expression might have occurred in tomato plants at the 10th day of cold exposure. The increased level of mRNA might have been sustained after 10 days, but as the plants start to lose their viability at this stage, we could not continue the experiments after this time period. Although the current study highlights some important factors in the regulation of $S O D$ gene expression under cold stress in tomato plants, further analysis is necessary to explain this complex interaction.

To overcome the limitations for plant productivity, and to improve crop yields under cold stress, it is important to understand the molecular mechanisms of stress responses in higher plants. The relationship between lipid peroxidation, $S O D$ enzyme activity, and $S O D$ gene expression profile was found to be a very significant indicator of the effects of cold stress in plants. Results of this study provide new perspective about the relationship among ROS accumulation, lipid peroxidation, $S O D$ enzyme activity, and gene expression profile in tomato plants under cold stress. The results also suggest that regulation of the $S O D$ enzyme in tomato might occur in more than one step, and the network regulating the $S O D$ pathway might be extremely complex.

\section{ACKNOWLEDGMENTS}

The authors would like to thank the Ankara University Biotechnology Institute for providing the real-time PCR equipment for this study.

\section{REFERENCES}

Beck EH, Fettig S, Knake C, Hartig K, et al. (2007). Specific and unspecific responses of plants to cold and drought stress. J. Biosci. 32: 501-510.

Bradford MM (1976). A rapid and sensitive method for the quantitation of microgram quantities of protein utilizing the principle of protein-dye binding. Anal. Biochem. 72: 248-254.

Brummell DA, Dal C, V, Lurie S, Crisosto CH, et al. (2004). Cell wall metabolism during the development of chilling injury in cold-stored peach fruit: association of mealiness with arrested disassembly of cell wall pectins. J. Exp. Bot. 55: 2041-2052.

Chomczynski P and Mackey K (1995). Short technical reports. Modification of the TRI reagent procedure for isolation of RNA from polysaccharide- and proteoglycan-rich sources. Biotechniques 19: 942-945.

Dai QL, Wang J, Feng B, Liu T, et al. (2009). Molecular cloning and characterization of a new peroxidase gene (OvRCI) from Orychophragmus violaceus. Afr. J. Biotechnol. 8: 6511-6517.

DalCorso G, Farinati S, Maistri S and Furini A (2008). How plants cope with cadmium: staking all on metabolism and gene expression. J. Integr. Plant Biol. 50: 1268-1280.

Dat J, Vandenabeele S, Vranova E, Van Montagu M, et al. (2000). Dual action of the active oxygen species during plant stress responses. Cell Mol. Life Sci. 57: 779-795.

Droillard MJ and Paulin A (1990). Isozymes of superoxide dismutase in mitochondria and peroxisomes isolated from petals of carnation (Dianthus caryophyllus) during senescence. Plant Physiol. 94: 1187-1192.

Farrell RE (2007). The Regulation of Gene Expression in Plants and Animals. In: Regulation of Gene Expression in Plants (Bassett CL, ed.). Springer Sci. + Business Media, LLC., New York, 1-38.

Fortunato AS, Lidon FC, Batista-Santos P, Leitão AE, et al. (2010). Biochemical and molecular characterization of the antioxidative system of Coffea sp. under cold conditions in genotypes with contrasting tolerance. J. Plant Physiol. 167: 333-342. 
Fridovich I (1995). Superoxide radical and superoxide dismutases. Annu. Rev. Biochem. 64: 97-112.

Goupil P, Souguir D, Ferjani E, Faure O, et al. (2009). Expression of stress-related genes in tomato plants exposed to arsenic and chromium in nutrient solution. J. Plant Physiol. 166: 1446-1452.

Gülen H, Çetinkaya C, Kadıŏlu M, Kesici M, et al. (2008). Peroxidase activity and lipid peroxidation in strawberry (Fragaria x ananassa) plants under low temperature. J. Biol. Environ. Sci. 2: 95-100.

Hodges DM, DeLong JM, Forney CF and Prange RK (1999). Improving the thiobarbituric acid-reactive-substances assay for estimating lipid peroxidation in plant tissues containing anthocyanin and other interfering compounds. Planta 207: 604-611.

Horvath I, Glatz A, Varvasovszki V, Torok Z, et al. (1998). Membrane physical state controls the signaling mechanism of the heat shock response in Synechocystis PCC 6803: identification of hsp17 as a "fluidity gene". Proc. Natl. Acad. Sci. U. S. A. 95: 3513-3518.

Lee SH, Johnson JD, Walsh MP, Van Lierop JE, et al. (2000). Differential regulation of $\mathrm{Ca}^{2+} /$ calmodulin-dependent enzymes by plant calmodulin isoforms and free $\mathrm{Ca}^{2+}$ concentration. Biochem. J. 350 Pt 1: 299-306.

Livak KJ and Schmittgen TD (2001). Analysis of relative gene expression data using real-time quantitative PCR and the $2(-\Delta \Delta C(\mathrm{~T}))$ method. Methods 25: 402-408.

Lyons JM (1973). Chilling injury in plants. Annu. Rev. Plant Physiol. 24: 445-466.

Mazzucotelli E, Mastrangelo AM, Crosatti C, Guerra D, et al. (2008). Abiotic stress response in plants: when posttranscriptional and post-translational regulations control transcription. Plant Sci. 174: 420-431.

McKersie BD and Leshem YY (1994). Salt Stress. Stress and Stress Coping in Cultivated Plants. Kluwer Academic Publishers, Dordrecht.

Mittler R (2002). Oxidative stress, antioxidants and stress tolerance. Trends Plant Sci. 7: 405-410.

Moran EF, Brondizio E, Mausel P and Wu Y (1994). Integrating Amazonian vegetation, land-use and satellite data. Bioscience 44: 329-338.

Örvar BL, Sangwan V, Omann F and Dhindsa RS (2000). Early steps in cold sensing by plant cells: the role of actin cytoskeleton and membrane fluidity. Plant J. 23: 785-794.

Payton P, Webb R, Kornyeyev D, Allen R, et al. (2001). Protecting cotton photosynthesis during moderate chilling at high light intensity by increasing chloroplastic antioxidant enzyme activity. J. Exp. Bot. 52: 2345-2354.

Pinhero RG, Rao MV, Paliyath G, Murr DP, et al. (1997). Changes in activities of antioxidant enzymes and their relationship to genetic and paclobutrazol-induced chilling tolerance of maize seedlings. Plant Physiol. 114: 695-704.

Posmyk MM, Bailly C, Szafranska K, Janas KM, et al. (2005). Antioxidant enzymes and isoflavonoids in chilled soybean (Glycine max (L.) Merr.) seedlings. J. Plant Physiol. 162: 403-412.

Prasad TK (1996). Mechanisms of chilling-induced oxidative stress injury and tolerance in developing maize seedlings: changes in antioxidant system, oxidation of proteins and lipids, and protease activities. Plant J. 10: 1017-1026.

Privalov PL (1990). Cold denaturation of proteins. Crit. Rev. Biochem. Mol. Biol. 25: 281-305.

Rao MV, Paliyath G and Ormrod DP (1996). Ultraviolet-B- and ozone-induced biochemical changes in antioxidant enzymes of Arabidopsis thaliana. Plant Physiol. 110: 125-136.

Roxas VP, Lodhi SA, Garrett DK, Mahan JR, et al. (2000). Stress tolerance in transgenic tobacco seedlings that overexpress glutathione S-transferase/glutathione peroxidase. Plant Cell Physiol. 41: 1229-1234.

Shinozaki K and Yamaguchi-Shinozaki K (2000). Molecular responses to dehydration and low temperature: differences and cross-talk between two stress signaling pathways. Curr. Opin. Plant Biol. 3: 217-223.

Shinozaki K and Yamaguchi-Shinozaki K (1996). Molecular responses to drought and cold stress. Curr. Opin. Biotechnol. 7: $161-167$.

Smirnoff FN (1993). The role of active oxygen in the response of plants to water deficit and dessication. New Phytol. 125: 27-58.

Tester M and Davenport R (2003). $\mathrm{Na}^{+}$tolerance and $\mathrm{Na}^{+}$transport in higher plants. Ann. Bot. 91: 503-527.

Tian L, Wang H, Abdallah AM, Prinyawiwatkul W, et al. (2011). Red and white wines inhibit cholesterol oxidation induced by free radicals. J. Agric. Food Chem. 59: 6453-6458.

Van Camp W, Willekens H, Bowler C, Van Montagu M, et al. (1994). Elevated levels of superoxide dismutase protect transgenic plants against ozone damage. Nat. Biotechnol. 12: 165-168.

Verma S and Dubey RS (2003). Lead toxicity induces lipid peroxidation and alters the activites of antioxidant enzymes in growing rice plants. Plant Sci. 164: 645-655.

Xu SC, Li YP, Hu J, Guan YJ, et al. (2010). Responses of antioxidant enzymes to chilling stress in tobacco seedlings. Agric. Sci. China 9: 1594-1601.

Wu CA, Yang GD, Meng QW and Zheng CC (2004). The cotton GhNHX1 gene encoding a novel putative tonoplast $\mathrm{Na}^{+} /$ $\mathrm{H}^{+}$antiporter plays an important role in salt stress. Plant Cell Physiol. 45: 600-607.

Zhang JZ, Creelman RA and Zhu JK (2004). From laboratory to field. Using information from Arabidopsis to engineer salt, cold, and drought tolerance in crops. Plant Physiol. 135: 615-621. 